
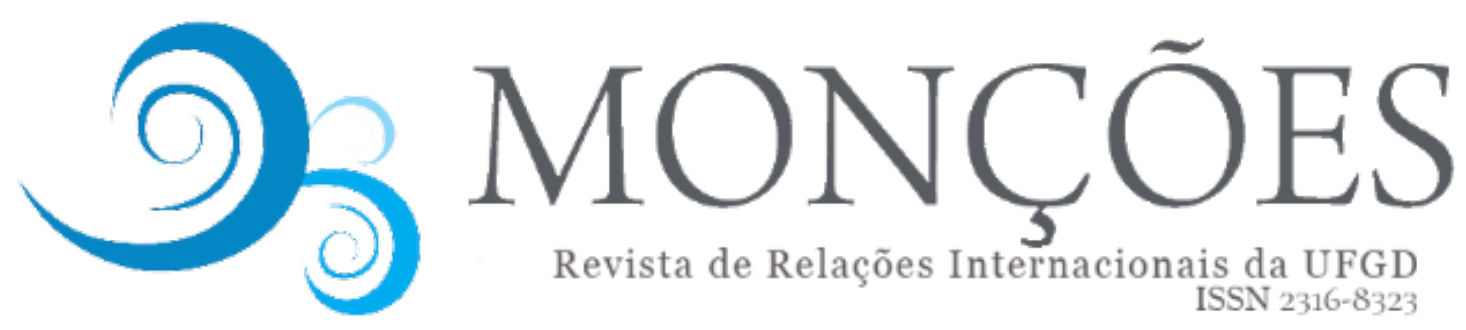

ISSN 2316-8323

\title{
PERSEGUIR O INATINGÍVEL: REPENSANDO A CONSTRUÇÃO DE AMEAÇAS A PARTIR DE UMA PERSPECTIVA LACANIANA*
}

\author{
LEONARDO MENDONÇA VENTURA \\ Mestrando em Relações Internacionais - IRI/Puc-Rio \\ E-mail: venturalm@outlook.com \\ RAFAEL MOSCARDI PEDROSO \\ Mestrando em Relações Internacionais - IRI/Puc-Rio \\ E-mail: rmoscardipedroso@gmail.com
}

\begin{abstract}
RESUMO: O presente trabalho tem como objetivo analisar as relações entre o conceito lacaniano de fantasia e a construção de ameaças. A ideia central do artigo é pensar como determinadas fantasias de segurança servem para sustentar a efetivação do que aqui se entende como a narco-necropolítica filipina. Entendemos o conceito de fantasia como uma narrativa imbuída de desejo através da qual os sujeitos fazem sentido do mundo. Dessa forma, argumentamos que, no campo da segurança, a fantasia é um mecanismo de produção de realidade que mobiliza um desejo inatingível por segurança e tanto promete uma solução simplificada das contradições, quanto acaba legitimando a classificação de outros como ameaças e o emprego de violência e de dispositivos de necropolítica por parte do Estado contra esses corpos. O trabalho surge motivado pelos esforços teóricos em teoria psicanalítica dentro de Relações Internacionais, além de dialogar com autores de outras disciplinas que utilizam esse instrumental de análise. Esperamos que esse artigo consiga desafiar alguns conceitos pré-estabelecidos em teoria de Relações Internacionais, especificamente em estudos de segurança, e demonstrar a importância da fantasia enquanto categoria de análise interessante para a compreensão da política internacional.
\end{abstract}

PALAVRAS-CHAVE: fantasia; desejo; ameaça.

\section{PURSUING THE UNATTAINABLE: RETHINKING THREAT CONSTRUCTIONS FROM A LACANIAN PERSPECTIVE}

ABSTRACT: This present work has as objective to analyze the relations between the lacanian concept of fantasy and the construction of threats. The central idea is to think how some fantasies of security sustain the effectivity of what we understand as the Philippine narco-necropolitics. We understand the concept of fantasy as a narrative imbued with desire through which the subjects make sense of the world. This way, we argue that, in the field of security, fantasy is a mechanism for the production of reality that mobilizes an unattainable desire for security and promises not only a simplified solution of contradictions but also ends up legitimizing the classification of others as threats and the deployment of violence and necropolitics by the State against those bodies. This work is motivated by the theoretical efforts in psychoanalytical theory inside International Relations, also engaging with authors from other backgrounds that realize similar analysis with these same concepts. We hope that this article challenges some established concepts in International Relations theory,

* O presente trabalho foi realizado com apoio da Coordenação de Aperfeiçoamento de Pessoal de Nível Superior - Brasil (CAPES) - Código de Financiamento 001. Gostaríamos, igualmente, de agradecer o trabalho do(a)s revisore(a)s, sua leitura cautelosa e suas contribuições para nossa pesquisa. 
specifically in security studies, and show the importance of fantasy as an interesting category of analysis for understanding international politics.

KEYWORDS: fantasy; desire; threat.

\section{Introdução}

Durante as "midterm elections" do presente ano, os Filipinos decidiram por aumentar a base de apoio do presidente Rodrigo Duterte no senado (AL JAZEERA, 2019). Agora, das 24 cadeiras existentes, 4 são ocupadas pela oposição e 20 por senadores alinhados ao bloco no poder (SANTOS, 2019). Entre aqueles que engordam a base de apoio de Duterte no senado encontra-se, por exemplo, Ronald de la Rosa - antigo chefe da polícia nacional filipina cuja candidatura teve como fio condutor a promessa de legalização da pena de morte para traficantes de drogas ilícitas (CALIWAN, 2019). Exatos três anos após o início do mandato de Duterte, tais eleições funcionam, grosso modo, como um mecanismo de medição do grau de aprovação que a população filipina faz do presente governo, sendo possível depreender a enorme popularidade da qual dispõem o governo, suas práticas e seus discursos vis-à-vis a população. Em especial, o resultado das eleições é uma importante ferramenta de análise da opinião dos filipinos frente uma das principais bandeiras e políticas levadas a cabo pela administração vigente: o projeto "Double Barrel".

Iniciada por Rodrigo Duterte quando de sua eleição, o projeto "Double Barrel" ou a nova política de drogas filipina já resultou em mais de vinte e sete mil assassinatos extrajudiciais de supostos traficantes e usuários de drogas ilícitas, de acordo com a Comissão de Direitos Humanos do país (MARU, 2018). Tal número nos aponta para o engendramento do que, aqui, consideramos como uma narconecropolítica. Para nós, se é correto que a necropolítica é a política de morte que tem origem na colônia (MBEMBE, 2018; PELBART, 2018), a narco-necropolítica é a política de drogas que recolhe e atualiza o imaginário racista colonial e cuja lógica não é outra senão a da maior "destruição material [possível] de corpos humanos" (MBEMBE, 2018, p. 10). 
$\mathrm{Na}$ esteira de Achille Mbembe, partimos do pressuposto de que "a expressão máxima da soberania reside, em grande medida, no poder e na capacidade de ditar quem pode viver e quem deve morrer" (MBEMBE, 2018, p. 5). Aqui, a soberania não é vista como um duplo movimento de "autoinstituição" e "autolimitação" por meio do qual um conjunto de sujeitos livres, iguais e racionais, "capazes de autoconhecimento, autoconsciência e autorrepresentação", "fixa em si os próprios limites para si mesmo"; tampouco pensamos a política como o "exercício da razão na esfera pública” (MBEMBE, 2018, p. 9-10). Ao contrário, o elevado número de mortos e o caráter agressivo dos discursos de Duterte sobre os usuários e traficantes de drogas ilícitas representam não uma ruptura ou negação do processo político "normal", mas, sim, "o nomos do espaço político em que ainda vivemos" (MBEMBE, 2018, p. 11).

Diferentes organizações que trabalham pela defesa dos Direitos Humanos no mundo, por sua vez, criticam o modus operandi com o qual essa política é exercida, acusando o governo de promover uma série de crimes contra a humanidade ao não respeitar procedimentos legais de julgamento e condenação dos acusados (THE WASHINGTON POST, 2019). Por outro lado, conforme supracitado, o resultado das eleições para o Senado nas Filipinas nos dá a sensação de que parte da população endossa a efetivação da política de drogas como uma política de morte, pois vê a si mesma representada nas práticas discursivas beligerantes que constroem os "usuários/traficantes" como figuras espectrais desprovidas de estatuto político e como principal obstáculo no caminho da realização daquilo que a sociedade filipina encara ser seu "destino manifesto" - tornar-se desenvolvida.

O presente trabalho emerge, pois, enquanto uma tentativa de compreender o teatro de operações que se encontra por trás dos corpos atirados ao chão nas ruas das cidades filipinas. Mais especificamente, estamos interessados em analisar as dinâmicas que tornam possível legitimar o dispêndio absoluto do negativo - o poder de morte - contra um conjunto específico de corpos - os usuários/traficantes de drogas ilícitas. Nesse sentido, no presente trabalho a nossa pergunta principal é: quais as dinâmicas que permitem, nas Filipinas de hoje, a encenação de uma narconecropolítica?

Entendemos que o avanço da administração Duterte por sobre esses corpos e sua consequente transformação em vida descartável, vida indigna de ser vivida e, 
por isso, vida matável, está intimamente conectado com um certo entendimento sobre o que é segurança, quais práticas e discursos de segurança são interessantes pensar e sobre quais são os atores relevantes nessa mobilização. Com isso em mente, para a construção desta análise e melhor exploração dos mecanismos através dos quais a narco-necropolítica é legitimada, gostaríamos, em primeiro lugar, de nos distanciar de uma concepção tradicional de segurança que tem como referenciais únicos os atores ditos tradicionais nas Relações Internacionais (o Estado e as forças armadas); concepção essa na qual a segurança é sempre correlata à guerra e à ameaça de sobrevivência do Estado no internacional (KRAUSE, WILLIAMS, 1996, 2018). Ao contrário, nos alinhamos a um modo crítico de pensar a (in)segurança que enxerga nela "uma forma de gestão da vida e de suas condições estruturais e sociais" (BIGO, 2008, p. 123) que leva como sua contraparte intencional a produção da morte.

Ademais, acreditamos que, para o esforço que aqui desenvolvemos, é interessante pensar (in)segurança como um conceito dialógico, intersubjetivo (BIGO, 2008: BUZAN, WAEVER, DE WILDE, 1998). Uma vez que a efetividade e o fazer funcionar de um certo discurso de guerra mediante uma "ameaça existencial" está condicionado, imperativamente, à sua aceitação por uma audiência específica (que nunca é dada antes mas aparece, necessariamente, através do próprio discurso de guerra), o emprego de "medidas emergenciais" para o tratamento da questão em jogo, para a distribuição do poder de morte, depende da circulação de narrativas que respaldem sua efetuação.

Da mesma forma, julgamos ser preciso trabalhar a (in)segurança também a partir das táticas micropolíticas e da circulação de saberes dos profissionais de segurança (BIGO, 2008), de modo que possamos compreender como a securitização não se resume ao ato performativo do estabelecimento da fronteira da emergência porque engloba, igualmente, toda uma série de microprocessos perpetrados no dia a dia dos agentes de segurança (sejam eles estatais, como, por exemplo, a polícia filipina, ou não estatais como é o caso dos esquadrões de morte). Em outras palavras, a securitização possui dimensões distintas, mas complementares. Ainda, gostaríamos de enfatizar que a segurança não é um bem público que ambiciona incluir a todos, mas, sim, uma prática discursiva que delimita 
zonas de segurança que existem justamente às custas da criação de zonas de insegurança (BIGO, 2008).

No presente trabalho, tentamos compreender o que se encontra por trás das narrativas que colocam o outro como ameaça e, principalmente, o que faz com que práticas como, por exemplo, o assassinato generalizado de supostos usuários/traficantes de drogas ilícitas, sejam não apenas aceitáveis, mas, também, objeto de desejo de uma dada população. Recorremos ao conceito de fantasia de Jacques Lacan e outras lógicas próprias da Psicanálise para construir nossa análise. Ao tentamos explicar o processo de formação de sujeitos e os meios através dos quais esses sujeitos se atrelam a determinados discursos, nosso objetivo é analisar as interseções entre fantasia, sujeito, desejo e (in)segurança de maneira que possamos fornecer uma diferente explicação dos motivos que levam a população filipina a apoiar e demandar o emprego de tecnologias necropolíticas para a "gestão das multitudes" (MBEMBE, 2018).

Inspirados em trabalhos como os de Jenny Edkins (1999), Andreja Zevnik (2016), Ty Solomon (2016), Jakub Eberle (2019) e Moran Mandelbaum (2016), um dos nossos esforços é reconhecer a fantasia - no sentido psicanalítico do termo como uma ferramenta de análise relevante na política internacional. Tais autores, no seu movimento transdisciplinar de interseção entre Relações Internacionais e Psicanálise (lacaniana), nos auxiliam na tarefa de entender os aspectos de constituição do sujeito em relação a determinadas fantasias e sua aderência a certos discursos políticos. Ao inserir a noção de "fantasia lacaniana" enquanto categoria possível para se (re)pensar a (in)segurança, defendemos a abertura de uma "zona de troca" entre as disciplinas de Relações Internacionais e a Psicanálise, de modo que, do câmbio de debates, conceitos e estratégias, possam nascer novas perspectivas para enxergar nossas próprias áreas de pesquisa. (EBERLE, 2019).

Para tanto, o trabalho será divido em três seções diferentes. Na primeira seção, centraremos nosso foco em traçar um mapa conceitual da tríade sujeitodesejo-fantasia conforme pensada pela tradição lacaniana, com o intuito de compreender os conceitos e suas interseções. Na segunda seção, analisaremos a maneira através da qual a tríade citada nos oferece um aparato interessante para pensar o tecido sócio-político e as dinâmicas de segurança que o permeiam. Nela, voltaremos nossos esforços para tentar compreender como a fantasia, enquanto 
instrumento através do qual os sujeitos se inserem no mundo e dele fazem sentido, está conectada com questões de gerenciamento da (in)segurança. Na terceira e última seção, tentaremos ilustrar o trabalho feito nas duas seções anteriores a partir de uma breve análise do atual contexto das Filipinas para, assim, fornecer uma nova interpretação sobre como fantasia e (in)segurança estão conectadas com as formas de legitimação da violência do Estado.

Finalmente, gostaríamos de deixar claro as diferentes possibilidades que um arcabouço conceitual psicanalítico pode proporcionar para o entendimento de fenômenos e processos sócio-políticos mundiais. Inserir a fantasia enquanto categoria de análise em Relações Internacionais captura, de modo frutífero, a integração entre sujeito e desejo e contribui para que pensemos como a própria ideia de segurança atua nos moldes de um significante vazio por sobre o qual se projetam diversas expectativas políticas. Mais do que isso, inserir a fantasia como categoria de análise em Relações Internacionais, e empregá-la para pensar a guerra às drogas, é um esforço que tenta contribuir para um diálogo já estabelecido entre as literaturas de Psicanálise e Relações Internacionais à medida que posiciona o sujeito fragmentado da Psicanálise como um locus importante de reflexões sobre política que se abrem para além da ficção do sujeito racional moderno. Trata-se, portanto, de um trabalho que não se propõe a esgotar o assunto abordado, mas que, ao contrário, serve ao encontro entre esses aportes teóricos e à possibilidade de abertura por mais pesquisas que nos auxiliem na tarefa de borrar as fronteiras entre Relações Internacionais e Psicanálise, em especial no Brasil.

\section{Situando sujeito-fantasia-desejo: Um breve mapa conceitual}

\subsection{Sujeito lacaniano: entre separação e alienação}

O sujeito lacaniano é definido por uma falha em se reconhecer como imagina e uma recorrência ao simbólico (à linguagem) para se definir e existir, sendo um "sujeito-do-significante". A subjetividade é marcada por essa fragmentação que "aparece como condição ontológica do sujeito como ela é" sendo o sujeito da psicanálise lacaniana, portanto, "O sujeito descentralizado, estruturado justamente por essa fragmentação" (GLYNOS, STAVRAKAKIS, 2008, p. 260). A "fase do 
espelho" ilustra essa fragmentação do sujeito Lacaniano e metaforiza o momento da primeira identificação ao se olhar em um espelho. Trata-se de uma das mais antigas contribuições de Lacan e foi baseada em experimentos de etologia e psicologia infantil na época. A cena da fase do espelho descreve o surgimento da fantasia na vida do sujeito, sendo a fantasia a intersecção entre o simbólico e o imaginário (LAPLANCHE, PONTALIS, 1973, p. 754). De maneira bastante simplificada, a cena do espelho é uma cena na qual a criança encara um espelho quando próxima de uma figura de autoridade, geralmente a mãe ou o pai.

Antes desse evento generativo da subjetividade, o sujeito vive o mundo apenas sob a sua perspectiva, como num jogo em primeira pessoa no qual ele só consegue imaginar a si mesmo através da forma como experimenta o que lhe é exterior. É importante notar que essa forma de existir é não simbolizável, ela não se manifesta como memória, mas suposto resíduo, uma experiência que é suposta, mas inacessível ao sujeito. O indivíduo experimenta sensações através de seu corpo, porém não tem a ideia sobre a forma desse corpo como um todo, apenas sobre o que vê e sente de maneira fragmentada (LACAN, 1987).

O sujeito lacaniano é definido por dois processos: alienação e separação. A alienação surge através do primeiro olhar da criança com a imagem como um todo, diferindo da anterior fragmentação experimentada. Quando o infante olha para sua imagem, ele vê algo essencialmente diferente de sua experiência corpórea diária. Tal experiência inaugura um descompasso inicial, uma vez que esse corpo com o qual se identifica nunca é cem por cento enquadrado na experiência anterior. Dessa forma, ele se identifica com essa imagem precariamente, tendo a experiência de si enquanto um corpo uno. Essa operação é análoga à ligação de uma comparação metafórica entre o corpo imaginado e o corpo no espelho; as partes do corpo são condensadas em uma imagem que implica a substituição de uma pela outra, de um corpo fragmentado pelo refletido no espelho (DOLAR, 1998, p. 19-25; LACAN, 1987, p. 96-104). Esse processo deixa sempre um resíduo de distorção, de não reconhecimento dentro daquela imagem.

A alienação é correspondente à função do imaginário. A entrada no imaginário, em termos subjetivos, se refere à construção do sujeito enquanto um ego, sua delimitação através da imagem e, em termos intersubjetivos, a importância da imagem nessas relações, que pode suscitar diferentes afetos no sujeito, de 
atração a ódio. A própria percepção imagética de outro sujeito como semelhante e, ao mesmo tempo, diferente de mim é fruto do caráter externo e precário da nossa identificação com nossa imago no espelho (LAPLANCHE, PONTALIS, 1973, p. 637).

A experiência de fragmentação delimita o ego enquanto uma entidade una ao invés da simbiose da criança acoplada à mãe. Tal evento fornece o pano de fundo para a segunda parte: a separação. Separação é a descoberta do Outro (no evento do espelho, a figura que geralmente está presente é a mãe frequentemente grafada como $\mathrm{m}(\mathrm{O})$ ther) sendo aquele que atribui a imagem a você, mediando sua identificação e do qual você se vê separado, ainda que semelhante. Essa separação da mãe rompe com um relacionamento de simbiose e inaugura o sujeito enquanto tal, tendo em vista que o sujeito perde o tipo de relacionamento que tinha com a mãe e ganha um nome e uma linhagem (BERLANT, 2014a, p. 86; LACAN, 1998; STAVRAKAKIS, 1999).

A entrada no Simbólico se refere à iniciação do sujeito na linguagem que é um mecanismo marcadamente pré-existente a ele. De fato, Lacan se inspira no conceito de Levi-Strauss de ordem cultural para descrever o simbólico em suas descrições sobre a cultura como sendo um conjunto de cadeias de significantes, uma estrutura social que precede o sujeito, mas que o define. Seguindo LeviStrauss, para Lacan a linguagem é da ordem de uma estrutura social primordial necessária para a inteligibilidade de todas as outras e que é definida pela sua incompletude, pela impossibilidade de uma simbolização perfeita (LACAN, 1988, p. 29; LAPLANCHE, PONTALIS, 1973, p. 1299).

Lacan nos direciona para o que ele vislumbra ser uma nova relacionalidade: se antes o relacionamento mãe e filho era um relacionamento dual, a entrada no simbólico inaugura uma estrutura triangular nas relações, que serão sempre mediadas pela ordem simbólica na figura do Outro. Vale notar que esse Outro, com O maiúsculo, é diferente do outro da alteridade simples referente ao imaginário e compreende uma alteridade mais radical (LACAN, 1988).

O Outro para Lacan é a ordem simbólica da maneira como é particularizada para cada sujeito, podendo se referir a uma outra pessoa desde que a outra pessoa ocupe tal função para o sujeito em questão. Ter o Outro incluso nas relações atesta, justamente, o condicionamento do desejo pelo olhar externo sempre em relação à 
estrutura simbólica, seja esse olhar transgressivo ou complacente com ela (LAPLANCHE, PONTALIS, 1973, p. 129).

Sendo assim, "O estágio do espelho é a fase na qual o indivíduo conhece sua totalidade e ao mesmo tempo se faz consciente sobre a fragmentação no centro de sua subjetividade". (MANDELBAUM 2016, p. 4). A subjetividade é antes de tudo um ato de sujeição através do qual o indivíduo, ao se sujeitar ao simbólico, ganha a possibilidade de reconstruir a si mesmo ao se ligar a diversas possibilidades de significantes disponíveis. Como resíduo do processo de entrada no simbólico, resta uma falta fundamental que se inscreve enquanto um traço daquele prazer excessivo que se supõe ter havido antes de se entrar no mundo da linguagem, chamado de jouissance. Aqui há um ponto importante: não só se constrói fantasias para ocultar a perda dessa unicidade pré-linguagem, mas essa própria ideia de que havia algo é uma fantasia, pois nunca se pode ter certeza de que esse prazer realmente existiu (GLYNOS, STAVRAKAKIS, 2008; STAVRAKAKIS, 1999).

Para Lacan, a fantasia se situa na dobra entre simbólico e imaginário. De acordo com ele tal conceito funciona como uma maneira de ir contra o que ele diagnostica como um foco excessivo apenas no imaginário na psicanálise de sua época. A leitura inaugurada por Lacan sobre a fantasia, que a lê como que permeada pelo simbólico e pelo imaginário dá a possibilidade de interpretá-la como um fenômeno social que só pode ser "a história da linguagem e das instituições (...) e da memória" (LACAN, 1998, p. 278, p. 436).

A falta acima exposta é trabalhada em Lacan nos moldes de uma condição ontológica do sujeito que nos leva a dois pontos importantes: de um lado, a dependência da entrada no simbólico e de um Outro para a formação da subjetividade e, de outro, a impossibilidade de uma formação identitária permanente, o que motiva o sujeito a tentar preenchê-la buscando certos objetos de desejo e se acoplando a determinados significantes. Assim, o sujeito Lacaniano é definido pelo não-essencialismo, pela dependência sócio-simbólica e por sua relação com uma "falta" ontológica que tenta encobrir (GLYNOS, STAVRAKAKIS, 2008; STAVRAKAKIS, 1999).

O sujeito constrói-se socio-politicamente, portanto, em torno da falta, movimentando-se na tentativa de se acoplar a diferentes significantes que o permitam preenchê-la temporariamente, sendo esses "preenchimentos" sempre 
contingentes e instáveis (STAVRAKAKIS, 1999). O sujeito lacaniano, pois, dança uma "dialética negativa da fixação parcial" (GLYNOS, STAVRAKAKIS, 2008, p. 261). Nela, o ritmo é ditado pela própria falta ontológica, seus passos se movem de lugar em lugar, tal como seu desejo se move de objeto em objeto (na busca de objetos no qual ele projeta a possibilidade impossível de eliminar tal falta).

A história desse sujeito em relação passa a ser a história de seu desejo e por quais objetos ele se desloca. Em outras palavras, "Subjetividade no trabalho de Lacan, assim, é ligada não apenas à falta, mas também às nossas tentativas de eliminar essa falta que, apesar de tudo, continua ressurgindo" (GLYNOS, STAVRAKAKIS, 2008, 261).

Para um sujeito como esse, a própria vida social passa a ser uma busca impossível por esse senso de fechamento e completude que são impossíveis, que acaba passando inevitavelmente pela busca de vários objetos e, ao mesmo tempo, pela impossibilidade de uma resolução nesse sentido. Devemos interrogar, assim, como os movimentos do desejo do sujeito lacaniano nos ajudam a entender sua condição.

\subsection{Fantasia, a promessa de gozo, o desejo e a política}

$\mathrm{Na}$ tradição lacaniana, "A fantasia nos fornece a chave de entendimento para compreender as várias maneiras às quais tentamos continuamente erradicar essa separação, essa falta e a ausência de um significado estável e inteligível pra vida" (MANDELBAUM, 2016, p. 3-4). Em face de um sujeito fragmentado e alienado de si, a fantasia surge enquanto um mecanismo através do qual os indivíduos inconscientemente lidam com a falta, atrelando-se a certos significantes difusos no social, transformando o desamparo em identidade de modo a suportar a realidade da vida social. Sendo assim, ela é um "tipo de narrativa imbuída de desejo através do qual os sujeitos constroem sua realidade social" (EBERLE, 2019, p. 1). É por meio dela que os indivíduos buscam objetos com uma promessa de gozo parcial, e closure, preenchimento dessa falta, têm seus desejos deslocados em direção a algum objeto específico. Segundo Stavrakakis (1999) p. 46, a fantasia é sempre uma relação: 
entre o sujeito fragmentado, o sujeito faltante e uma promessa de eliminação dessa falta ou uma compensação por ela, algo que consiga neutralizá-la estruturalmente. Se a condição humana é marcada pela busca por um gozo perdido/impossível, a fantasia nos oferece a promessa de um encontro com essa jouissance perdida, encontro que é fantasiado enquanto cobrindo a falta no Outro, e, por consequência, cobrindo a falta no sujeito.

De uma certa forma, é um movimento duplo: a fantasia de um lado oculta a encruzilhada original da fase do espelho (manifesta nos movimentos de alienação e separação) e projeta, em um passado imaginário fantasmático, um período fundamentalmente melhor e menos contraditório, repleto de uma jouissance perdida. Vale notar que, apesar da cena de uma fantasia primordial na inauguração da subjetividade, na existência social estamos diariamente submetidos a várias e distintas fantasias às quais temos apegos diferentes, i.e., nos acoplamos a diferentes significantes e objetos na tentativa de "preencher" nossa falta ontológica (STAVRAKAKIS, 1999).

É importante notar dois pontos cruciais na articulação da tríade fantasiadesejo-objeto. Primeiramente, a fantasia, enquanto "processo através do qual sujeitos (atores sociais) se relacionam com a realidade e reproduzem estruturas sociais" (EBERLE, 2019, 3), nos dá as coordenadas do desejo, disciplinando-nos sobre quais objetos desejar, nos deslocando de objeto em objeto e condicionando a nossa experiência na teia sócio-política. Essa escolha objetal não é neutra e aleatória, mas carregada pela influência da história e das relações de poder que circulam no social (STAVRAKAKIS, 1999).

Em segundo lugar, projeta-se nesses objetos desejados uma possibilidade de prazer excessivo, acima definida como jouissance. A jouissance é caracterizada como a possibilidade de um gozo excessivo derivada da obtenção de um objeto do qual, contudo, nunca se dispõe. O gozo dos sujeitos será sempre parcial e nunca alcançará a projeção imaginária, fazendo com que o sujeito continue em busca de outros objetos na tentativa de manter, com quantias módicas de prazer, sua estabilidade. Em outras palavras, a história de um sujeito é a história de como o seu desejo se move de objeto em objeto tentando, por um lado, apaziguar essa contradição e, por outro, produzir efeitos concretos na vida e existência sócio-política do sujeito (STAVRAKAKIS, 1999; BERLANT, 2014a; BERLANT, 2014b). 
A jouissance é, pois, figura importante no processo de construção e articulação de fantasias pois é a partir dela ou, melhor, na expectativa de sua realização, que vemos surgir os fantasmas. No desejo, o objeto "a" são os objetos que carregam a possibilidade deplenitude desejada. Apesar de nunca serem atingidos, os objetos "a" gerenciam os desejos e circulam entre as narrativas que conectam o social. Por isso esses objetos são chamados metonímicos pois são desejados enquanto uma parte de um certo "todo" ditado pela fantasia, estando sempre presentes nos cálculos do desejo influenciando a forma com a qual lidamos com e produzimos o social (STAVRAKAKIS, 1999).

Sendo assim, identificar uma fantasia na vida política passa pelo reconhecimento de certas características. Uma estrutura de um cenário ideal que consiga ocultar contradições, eliminar antagonismos de maneira simplificada (a conspiração judaica na fantasia nazista, por exemplo); objetos aos quais se permite desejar e que prometem o atingimento desse ideal (a ideia de que há um objeto que possa trazer a condição de segurança como, por exemplo, uma arma ou uma forma de policiamento); uma promessa de resolução de contradições e/ou estabilização da própria identidade (ao afirmar um outro como culpado reificamos quem somos, voltamos para a relação amigo/inimigo) (EBERLE, 2019; ZIZEK apud PROUDFOOT, 2017).

A fantasia, assim, nos apresenta um caminho para o gozo-jouissance colocando-a no outro, condicionando o gozo ao olhar do outro seja quando nos comportamos de maneira a agradá-lo, quando nos fazemos de objeto dele ou, ainda, quando acreditamos que ele roubou de nós a nossa capacidade de gozar - o "roubo de jouissance". Essa ideia de roubo de jouissance é vista em ação quando pensamos em fantasias racistas que conseguem imaginar imigrantes como aqueles que roubam nossos empregos e, ao mesmo tempo, aqueles que não trabalham e são preguiçosos. Como Janus ${ }^{1}$ que consegue existir com suas duas faces, a contradição na fantasia consegue coexistir facilmente (LACAN, 2016; ZIZEK, 1997).

A última peça para a compreensão da fantasia é aquilo que Zizek chamou de transgressão inerente. De acordo com Zizek, "Para ser operativa, uma fantasia deve

\footnotetext{
${ }^{1} \mathrm{O}$ mito de Jano pertence à mitologia romana. Jano (ou Janus), divindade ligada às transformações e mudanças, era representado com duas faces, uma jovem simbolizando o futuro e uma velha representando o passado. As duas faces de Jano, olhando para direções opostas, significam a dualidade inerente a todas as coisas, seu dualismo relativo.
} 
permanecer implícita, mantendo certa distância da textura simbólica explicita sustentada por ela, funcionando como sua transgressão inerente" (ZIZEK, 1997, p. 24). A transgressão é o "suplemento obsceno" da fantasia no sentido em que, para o autor, o próprio edifício ao se estabelecer não só permite a transgressão de sua própria retórica, mas como o próprio poder se sustenta através da continuidade dessa transgressão. (ZIZEK, 1997).

Se tomarmos o exemplo da soberania estatal, a sua própria implantação, paradoxalmente, tanto aparece como uma solução a um cenário de violência ao mesmo tempo que é permeada tanto por um uso sistemático da violência quanto pela própria ocultação da violência em que essa fundação implica. Ironicamente uma das maneiras de minar uma fantasia seria não subvertendo-a propositalmente - já que esse desvio algumas vezes é esperado e facilmente manejado - mas se identificando excessivamente com ela, exercendo a sua atividade excessivamente a ponto de expor a própria transgressão que funda a ordem, levando-a às últimas consequências (ZIZEK, 1997).

Dentro do caso filipino, a preocupação é menos em entender o que a fantasia esconde sobre os usuários de drogas - já que é óbvio que ela não corresponde à realidade da toxicomania - e mais compreender o que essa fantasia como tal permite que opere. No caso, a própria narco-necropolítica enquanto uma trivialidade do sistema que só tem seu horror evidenciado pela maneira escrachada e chocante que o discurso de Duterte legitima a política de morte.

Em uma coletiva de imprensa em 2016, Duterte fez a equivalência entre o papel de Hitler na Alemanha no extermínio dos judeus e o seu papel no extermínio dos usuários de drogas pela operação que instaurou no país. Isso já evidencia o lugar discursivo do usuário de droga em suas práticas: o lugar daquele que deve ser extirpado, exterminado, o não-lugar (HOLMES, 2016).

Talvez o que torne o caso filipino chocante não seja, necessariamente, o emprego de violência contra a população de supostos usuários/traficantes de drogas ilícitas, nem o descaso para com essa população. Esse cenário é visualizado em vários países e é a norma em diversas partes do mundo (como no Brasil, por exemplo). Mais impactante do que isso é o fato de Duterte se identificar excessivamente com a capacidade soberana de traçar linhas de morte, levando-a às últimas consequências e causando, nesse sentido, grande espanto não por realizar 
um extermínio maior e mais cruel do que qualquer outro, mas por não se importar o suficiente em não expor sua dimensão de violação, quebrando um certo acordo tácito em manter um cinismo que nega a dimensão violenta e inerente à soberania (ZIZEK, 1997).

Nessa discussão, cabe o exemplo mobilizado por Zizek acerca dos arquivos que demonstravam a existência de tortura em Guantánamo: não era como se eles expusessem algo do qual as pessoas não desconfiassem ou que elas, subterraneamente, não conhecessem; o problema, em verdade, era trazer, para o topo debate público, um tema - a existência de tortura em Guantánamo - em face do qual as pessoas estavam confortáveis demais em ignorar. Mutatis Mutandis, o ponto não é a excepcional atrocidade de Duterte, mas, sim, que ele expõe a própria violência da atividade soberana de traçar zonas de (in)segurança e se utiliza delas como ganho de capital político, expondo a própria contradição desta lógica. É navegando por esse excesso que se abre um espaço interessante de questionamento dessas práticas (ZIZEK, 1997; CONDE, 2018).

Uma pergunta fundamental que não deve ser esquecida: por que fantasia e política? É no campo político que encontramos discursos que prometem aos cidadãos certos cenários: a boa vida, a sociedade justa e desenvolvida, a possibilidade de segurança. Não seriam esses cenários imaginários uma fantasia pura que nos condiciona a agir e a desejar certas coisas na esperança de alcançar um futuro imaginário, ordeiro, sem contradições? Ou, ainda, não seriam as presenças fantasmagóricas, elas próprias, o sustentáculo de vários projetos políticos como quando, por exemplo, nos defrontamos com a narrativa de um passado glorioso, interrompido por um inimigo que toma de nós nossa glória e nos leva a um presente miserável (a evocação quase mítica do Reino de Salomão e Davi pelo nacionalismo judaico, por exemplo) (GLYNOS; STAVRAKAKIS, 2008).

É importante notar que a disciplina de Relações Internacionais coloca a soberania como o significante sob o qual a política se faz e se concretiza, como o ideal regulador do que entendemos como subjetividade moderna, e como modelo de ação política. É ela o significante-mestre para a disciplina e para a vida política (BIGO; WALKER, 2007; EDKINS, 1999; WALKER, 2002). A soberania é o que possibilita o surgimento da lei, da justiça e de ideias de progresso e permite também 
delimitar o limite de uma sociedade, construir uma política no sentido de gestão das populações (WALKER, 1993).

Como em Walker (2002, p. 12), a soberania é frequentemente associada a uma capacidade de autodeterminação e ao mesmo tempo a uma capacidade de autorizar ou desautorizar e, portanto, uma posição de distribuição de decretos e julgamentos. Outrossim, a soberania funciona, em última instância, como uma ambição universalizada e reguladora da vida política, na qual o alcance de liberdade só pode ser efetivado em relação a esse significante, seja esperando pela sua realização plena ou rejeitando-o veementemente. A soberania, portanto, se torna modelo de ação regulador do horizonte político (WALKER, 2006, p. 62).

Tomada como reguladora, ela é relacionada a um decisionismo derivado do privilégio real que, se tomado como a regra de ação política, acaba gerando um modelo de subjetividade e agência que não concorda em nada com o mencionado acima sobre a tríade sujeito-desejo-fantasia que reforça questões inconscientes que escapam por fora dessa capacidade de decidir enquanto ato racional (BERLANT, 2013, p. 94).

A soberania se firma enquanto uma fantasia no sentido em que é uma "posição aspiracional de performatividade e auto-legitimação pessoal e institucional" (BERLANT 2013, p. 97). Isso não é uma afirmação sobre a irrelevância da soberania no campo político. Ao contrário, sua relevância perene é explicada justamente por ser um estado mais aspiracional do que objetivo. A soberania é enxergada como uma fantasia que provê a superfície sobre a qual regula-se a política e em cima da qual os desejos de autodeterminação, prosperidade, felicidade e realização são regulados.

O que está em questão na escolha das Filipinas como o caso ilustrativo, portanto, é justamente que Duterte se identifica excessivamente com essa fantasia soberana de agência e de direito de exercer uma necropolítica no seu uso explícito. Isso se refere ao que Zizek (1997) fala sobre a superidentificação como algo que perturba o horizonte fantasmático. De acordo com ele, se alguém se mostrar excessivamente tomado pela injunção do modelo de ação fantasmático, tal identificação demonstra a arbitrariedade da fantasia em si. No caso de Duterte, ele corporifica um modelo de agência soberana que reitera para a população a 
soberania de seu próprio país enquanto matéria de gozo, que, entretanto, expõe, no mesmo movimento, a própria arbitrariedade desse imaginário.

Outra pergunta persiste: se essas narrativas nos oferecem uma identificação momentânea, por que os sujeitos continuam acreditando nelas quando esse futuro idealizado não se realiza? Se voltarmos ao desejo e sua dinâmica de fluidez entre objetos, nos deparamos com um paradoxo importante: ao mesmo tempo que nunca nos reencontramos com a jouissance primordial que acreditamos ter perdido após a entrada no simbólico, recebemos uma jouissance módica quando atingimos certo objeto, e é a possibilidade de continuar recebendo essa jouissance módica que dá conta de nos manter agindo como se acreditássemos na promessa simplificadora da fantasia, ainda que, no fundo, "racionalmente" saibamos que ela não é real (GLYNOS, STAVRAKAKIS, 2008).

Ao mesmo tempo que essas narrativas parecem imediatamente dispensáveis, a maneira como a fantasia apazígua as contradições pode ser bastante rudimentar. Para exemplifica isso, basta que lembremos do imigrante que é representado como o vagabundo que não trabalha e se apropria de benefícios sociais e como aquele que se sujeita a todo tipo de trabalho excessivo e rouba o emprego dos cidadãos (EBERLE, 2019).

Vale notar: não é suficiente desvendar o real por trás da fantasia, desfazendo uma certa ilusão, mas precisamente o oposto, i.e., encontrar o que há de real na própria construção dessa fantasia que vivemos - o que a fantasia esconde é, também, criado no processo de ocultação. Face a uma conspiração (maçônica, judaica, marxista cultural etc.) devemos menos buscar os indícios de que ela não é real do que entender o que ela tenta, desesperadamente, esconder mesmo com todas suas contradições: precisamente, a contingência e o horror de um mundo (ZIZEK, 1997, p. 41).

Recapitulando, o trajeto percorrido por fantasia, desejo e subjetividade nos mostra que a fantasia se insere em uma zona interessante. Não é nem puramente objetiva, pois condiciona a maneira como os sujeitos veem o mundo, como, tampouco, é completamente subjetiva, pois irredutível à consciência individual. A fantasia, em última instância, sustenta o que chamamos de realidade e é a lente pela qual nos relacionamos com o mundo (STAVRAKAKIS, 1999, p. 35). 
Sendo "objetivamente-subjetiva", a fantasia tem um papel fundamental pois, longe de ser algo ilusório a ser dissipado, molda por si só a maneira como percebemos e agimos por sobre a realidade, legitimando, nesse caminho, certas políticas em detrimento de outras. Ainda, ao mesmo tempo que a fantasia legitima muito do que acontece em nossa prática política trivial, investigar a fantasia e atravessá-la abre possibilidade para uma nova relação com as subjetividades e, portanto, para um novo horizonte do político (EDKINS, 1999).

\section{3. (In)segurança, fantasia e necropolítica}

Cabe, agora, nos direcionarmos para pensar as imbricações entre fantasia, (in)segurança e violência de modo que sejamos capazes de desvelar, mais à frente, algumas das narrativas que atravessam e legitimam a narco-necropolítica filipina. Nesse sentido, ao tomarmos como ponto de partida os conceitos lacanianos abordados, vemos surgir uma "zona de contato" entre Relações Internacionais e Psicanálise que abre caminho para que possamos (re)pensar a (in)segurança no internacional.

A segurança, ao operar enquanto uma narrativa fantasiosa através da qual os indivíduos buscam suprir uma "falta ontológica", se mantém como uma "possibilidade-impossível", uma figura fantasmática que "continuamente tenta se materializar ao mesmo tempo que inclui seu próprio fracasso" (MANDELBAUM, 2016, p. 2). É na fantasia de segurança do eu (segurança ontológica) e do nós (segurança pública) que objetos de desejo são gerenciados e os obstáculos delineados. Securitizar, assim, para além de ser um movimento de saída do político e estabelecimento de um estado de emergência em um determinado assunto - a inversão do aforismo de Clausewitz - (BUZAN, DE WILDE, WAEVER, 1998), é a incessante produção e alteração de objetos de desejo e a subsequente alocação da culpa. É ali, entre o gozo na captura do objeto de desejo e o fracasso em alcançá-lo, que a culpa é alocada e ocorre a transferência do tratamento da questão para um nível acima do político, um nível securitizado.

Enquanto fantasia, a segurança é uma história, uma narrativa dentro da qual a falta ontológica do sujeito é racionalizada e atribuída à ausência de um "objeto" 
empírico específico em direção ao qual se desenha um curso de ação e cuja recaptura promete o gozo da identidade completa - "uma busca sem fim pela superação da falta e da contingência da vida social, oferecendo um futuropreechimento" (MANDELBAUM, 2016). A recaptura desse objeto passa, diretamente, pelo estabelecimento de obstáculos e barreiras a sua realização, sendo a figura do Outro de especial importância para a análise que aqui se desenrola. $\mathrm{Na}$ fantasia de segurança nacional, por exemplo, o Outro é aquele culpado pelo caos e pela desordem supostos vis-à-vis um passado de glória nacional - o caso do discurso contra os refugiados na Europa de hoje, por exemplo ou o papel do judeu na fantasia nazista (GLYNOS, STAVRAKAKIS, 2008).

Se nos atentarmos para a inversão na interpretação de Foucault de Hobbes do aforismo Clausewitziano, colocando a política como continuação da guerra por outros meios, podemos observar a relação entre soberania e guerra sob um ângulo diferente. A política enquanto continuação da guerra nos coloca nos termos em que o relacionamento social principal é de antagonismo e inimizade. O relacionamento de guerra, portanto, não é mobilizado como uma forma de oposição à soberania, mas enquanto preservação: a condição de possibilidade para a superação do Estado de natureza é a implantação de um regime de poder/verdade que é, por definição, arbitrário e que apaga essa arbitrariedade de sua origem, baseando sua universalidade na conversão de diferença em alteridade, substituindo a guerra contra todos do "estado de natureza" por um regime de segurança (SPIEKER, 2011, p. 191-194).

Ao traçar sua análise sobre o desenvolvimento do biopoder ${ }^{2}$, Michel Foucault nos alertava sobre a entrada do desejo no interior dos cálculos explícitos das técnicas de poder (FOUCAULT, 2008). De acordo com ele, o desejo, para além de diversas outras tecnologias e mecanismos que se agrupam em dispositivos disciplinares e securitários, é parte central na gestão das populações, uma vez que é através dele, do "jogo do desejo", da sua modulação, do direcionamento de seu

\footnotetext{
${ }^{2}$ De acordo com Foucault, o biopoder é um tipo de poder característico às sociedades modernas e que aparece como que acoplado ao poder soberano a partir de meados do século XVII e início do século XVIII. Diferentemente do poder soberano, o biopoder se ocupa de permitir a vida mais do que produzir a morte. Ao contrário da máxima "fazer morrer, deixar viver" que marca o poder soberano, a entrada do biológico nos cálculos de poder é dada através de um "fazer viver, deixar morrer" do qual se encarregam tecnologias disciplinares - anátomo-política do corpo - e biopolíticas - voltadas para aquilo que o autor chamou de homem-população (FOUCAULT, 2008, 2010).
} 
fluxo, do seu disciplinamento, que é possível produzir um certo "interesse coletivo", a vontade nacional. Enquanto narrativa imbuída de desejo, a fantasia ${ }^{3}$ de segurança permanece como uma figura espectral ou fantasmagórica construída a partir da circulação, por entre os sujeitos de um determinado Estado, de desejos (coletivos) por certos objetos. Essa canalização dos desejos abre espaço para a securitização daquilo que se busca alcançar e para a tomada da vida pelo poder.

De maneira similar, a fantasia também se faz presente no necropoder de Achille Mbembe. Ao tomar o caso da ocupação colonial contemporânea da Palestina enquanto exemplo paradigmático de necropoder, Mbembe aponta a forma como "violência e soberania" estão inextricavelmente implicadas na construção e difusão de narrativas (fantasiosas). De acordo com o autor, por exemplo, "O Estado colonial tira sua pretensão fundamental de soberania e legitimidade da autoridade de seu próprio relato da história e da identidade", apoiando-se, para isso, em todo um conjunto de saberes como "história, geografia, cartografia, arqueologia" a fim de sustentar e "naturalizar" sua identidade (MBEMBE, 2018, p. 42). Nesses espaços, a identidade nacional é imaginada e gerenciada, necessariamente, enquanto a “identidade contra o Outro" (MBEMBE, 2018, p. 42).

Em uma determinada sociedade, essas narrativas podem estar construídas de diferentes formas sendo o gozo, por sua vez, atribuído a objetos de desejo distintos - como, por exemplo, o desenvolvimento ou a identidade nacional previstos mediante a superação de obstáculos específicos - como a pobreza ou o imigrante. Conforme já apresentado, a captura do objeto de gozo nunca é bemsucedida restando aos sujeitos, animados por essas figuras fantasmagóricas que continuam a moldar o social, satisfazerem-se com o gozo módico ao mesmo tempo em que atualizam não só os objetos de desejo como, igualmente, os obstáculos à sua captura.

Movida pelo desejo de segurança, a fantasia cumpre, aqui, uma função específica: seja através da sua promessa de planificação ou da solução final (e simplista) das controvérsias, ela é aquilo que, como plataforma de sustentação de

\footnotetext{
${ }^{3}$ Apesar de Foucault não falar abertamente ou empregar de maneira direta a concepção lacaniana de fantasia em suas obras e ter utilizando, ao contrário, o conceito de "regimes de verdades", observamos ser possível traçar um paralelismo entre as ideias de ambos os autores, Lacan e Foucault, de modo a continuar nosso exercício de experimentação e de construção de zonas interdisciplinares de contato (EBERLE, 2019).
} 
outros mecanismos como o racismo, vai estabelecer um estado de sítio permanente e legitimar a violência do Estado no cotidiano, o fazer valer do velho direito soberano de espada em uma linguagem mais foucaultiana, ou, a partir do dicionário de Mbembe, a necropolítica como política de Estado. Em outras palavras, o que queremos dizer aqui é: a fantasia que emoldura a história como uma paisagem simplificada com seus antagonismos é, também, o que permite a aplicação do poder de morte tanto no biopoder foucaultiano (por meio da estatização do biológico e da interpretação da diferença através da lente da raça, o racismo de Estado) quanto no necropoder de Mbembe (onde a identidade nacional é pensada enquanto a identidade contra o Outro $)^{4}$.

Nessas fantasias, os indivíduos, motivados pelo desejo de segurança e defrontados tanto com a possibilidade de uma segurança ontológica (a identidade moderna, a identidade nacional), quanto com a promessa de uma vida boa, pujante e duradoura possíveis a partir da superação daquilo que os privam de alcançá-la, justificam e tornam aceitáveis o emprego de métodos, sejam eles quais for, para alcançar seu objeto de desejo. É isso que está no centro do entrelaçamento simbiótico entre a política e a guerra. É isso que faz da política a guerra. $\mathrm{Na}$ promessa da resolução, a securitização de uma questão é precisamente o que permite que contra ela sejam empregadas quaisquer soluções por mais violentas que sejam (WALKER, 1997). A mobilização da metáfora da guerra permite que quaisquer transgressões sejam feitas para que a "ameaça maior" - que não está definida a priori pois é sempre contingente no tempo e no espaço, estando seu enquadramento dependente de fatores específicos e das relações de poder que atravessam a construção da ideia de ameaça em questão - seja erradicada (BRASILINO, 2018).

Dessa forma, mais do que meio de fazer sentido do mundo e nele se inserir, a fantasia de segurança é um mecanismo que influi nos dispositivos de controle e gestão das populações e multitudes, sejam eles disciplinares, de segurança ou

\footnotetext{
${ }^{4}$ Para Foucault, só é possível expôr à morte no biopoder através aplicação do "racismo de Estado" ou, em outras palavras, da interpretação da diferença a partir de uma lente racial, onde a morte do outro aumenta exponencialmente a possibilidade da vida daqueles que se diz proteger - o perigo é da ordem do biológico (FOUCAULT, 2010). No necropoder de Mbembe, por outro lado, o poder de morte não está submetido a qualquer regra e já não se limita ao fardo da raça, mas encontra-se alinhado a um "devir-negro" do mundo, onde o lote de sofrimento antes reservados às pessoas pretas é, agora, expandido a toda uma multitude de indivíduos e corpos (MBEMBE, 2018; PELBART, 2018).
} 
necropolíticos. Em outras palavras, as fantasias de segurança vão oferecer as narrativas de legitimação das ferramentas de gerenciamento da (in)segurança e do controle (e destruição) dos corpos.

É ali, no seio do cruzamento entre as múltiplas narrativas fantasiosas, beatificadas ou transgressivas (a face de Jano), que a simbiose entre fantasia e (in)segurança se faz mais perceptível. A fantasia de segurança, dessa forma, com sua sociedade sob efeito de tranquilizantes, ordeira e desenvolvida funciona como um mecanismo por meio do qual vida é gerenciada e a morte distribuída.

\section{Um olhar sobre as Filipinas}

As Filipinas apareceram, recentemente, no radar internacional após a eleição de Rodrigo Duterte à presidência do país. Conhecido como "justiceiro" no território nacional - fama adquirida após o período em que ocupou o posto de prefeito da cidade de Davao -, Duterte ganhou notoriedade e simpatia dos filipinos ao explorar, de maneira beligerante, pautas de grande clamor popular. Em especial, o populismo violento de Duterte tomou como seu inimigo número um a questão da comercialização e do uso de drogas tornadas ilícitas dando início, conforme anteriormente colocado, a uma nova política de drogas.

Na presente seção, o nosso objetivo é olhar para a narco-necropolítica filipina de modo que possamos dar a ver as fantasias e os desejos que a endossam. Se o necropoder mobiliza uma dinâmica particular de fantasia, cabe perguntar: quais as principais narrativas que estruturam o caso filipino? Quais desejos elas endossam? O que justifica a grande aderência a essa narrativa?

Antes, faz-se necessário um rápido deslocamento. Conforme vimos, para os lacanianos o sujeito fraturado é parte constituinte da política moderna, pois é a partir dele que é possível mobilizar as fantasias do Estado-nação, do estado de natureza, da necessidade de segurança. Igualmente, se é o Estado, hoje, princípio ordenador do espaço político mundial, o sujeito lacaniano aparece como que espraiado, não está preso a um ou outro lugar, é condição estruturante do que entendemos por Sistema Internacional. Se os sujeitos fraturados existem em todos os lugares, se eles são parte constituinte de toda a política moderna, se é a partir de um sujeito fraturado que podemos mobilizar a fantasia do Estado-nação e da segurança, por 
que focar nossa análise no caso das Filipinas? A escolha das Filipinas para ilustrar nossa argumentação não é aleatória. O que faz com que o quadro filipino seja mais interessante de ser analisado a partir do repertório conceitual ao qual recorremos é, precisamente, a proporção do caso, a dramaticidade que o enreda e a dinamicidade dos agenciamentos que são traçados entre os atores que costuram aquela teia social.

De maneira geral, a cena que visualizamos no caso filipino é a seguinte: De um lado, encontra-se o Estado enfraquecido de sua potencialidade e desvirtuado de seus propósitos pelo narco-Estado; do outro, estão os adictos/traficantes, figuras espectrais desmoralizadas, promíscuas e ruins - o outro - que impedem, imperativamente, que a nação prospere; e, finalmente, ali, cercados entre um "Estado falido" e aqueles que o usurparam, encontram-se os bons e inocentes cidadãos mergulhados em um cotidiano violento e inseguro resultante do problema das drogas.

Para a análise que estamos tentando realizar, a principal narrativa que encontramos no caso filipino é a de uma sociedade sitiada e ameaçada pelo fantasma do narco-Estado - a fantasia da insegurança. Nela, os cidadãos encontram-se encurralados pela promiscuidade da comercialização e do uso de drogas ilícitas, que já não se inscreve somente nos corpos daqueles moralmente "fracos", como, fundamentalmente, contamina toda a esfera da vida pública e transforma o Estado em um maquinário esquizofrênico onde, paralelamente à lei, está uma organização virulenta pautada pela narco-economia - laissez-faire do tráfico de drogas. Segundo esse discurso, o Estado-nação funcionaria como um hospedeiro e o narco-Estado ocuparia a posição de um parasita que se beneficia dele causando-lhe complicações e prejuízos. Contudo, tal como em uma relação de coadaptação, os danos investidos ao hospedeiro pelo parasita não podem ser suficientes para provocar a morte do primeiro, uma vez que a sobrevivência do segundo depende da sobrevivência do primeiro.

Nessa fantasia, o narco-Estado é o principal obstáculo que a sociedade filipina encontra no caminho para a realização daquilo que seus cidadãos mais desejam: uma vida boa, segura e desenvolvida. Esse desejo, contudo, ganha uma nova dimensão no nosso caso. Uma vez que o "atraso", o "subdesenvolvimento" encontra-se ligado ao que, no presente, resta de um passado colonial, o narco- 
Estado - para alguns, o "Estado falido" - é, assim, uma lembrança aos filipinos de seu passado colonial; i.e., é uma rememoração da racionalidade racista do projeto colonial que marcava os corpos dos "selvagens" como incapacitados, geneticamente, de construir sua própria história. Aqui, combater o narco-Estado se torna uma luta anticolonial, uma luta pela identidade filipina.

Um olhar mais atento para a relação entre Estado-nação e narco-Estado nos aponta que essa dicotomia entre duas entidades estanques não captura a maior complexidade que envolve o relacionamento entre ambos os agentes (ou seriam fantasias?). Da mesma forma que o narco-Estado se beneficia e depende do Estado-nação para se manter, o próprio Estado-nação depende da existência de um narco-Estado, e de todos os inimigos espectrais construídos em torno dele, para justificar o emprego e o uso da violência a fim de realizar a sua própria preservação e a razão de Estado. Queremos dizer com isso que as fronteiras entre Estado-nação e narco-Estado não são muito bem delineadas, que elas são mais fluidas e que estão, a todo momento, sendo redesenhadas e disputadas de modo que, em alguns instantes, é impossível separar narco-Estado de Estado-nação como, por exemplo, nos mostra o filho de Rodrigo Duterte, Paolo Duterte, ao ser acusado de estar envolvido em uma grande operação de tráfico internacional de drogas ilícitas (BBC, 2017). Em um caso como esse, em que o próprio ator estatal está aliado àquilo que diz ser seu inimigo, onde está a fronteira que distingue Estado-nação e narcoEstado?

Nesse sentido, o narco-Estado não é apenas um parasita para o Estadonação, tampouco é apenas seu duplo, a outra face de Jano. Enquanto uma fantasia maior que organiza as sociedades modernas, o Estado está para além das duas faces de Jano, pois possui uma multiplicidade de faces, de fantasias distintas que se agenciam em lugares específicos e que informam e costuram a comunidade política em uma teia fantasiosa composta de arranjos muito mais complexos do que as explicações rápidas e binárias que são circuladas para capturar nossos desejos.

Tão importante quanto a narrativa supracitada é o papel desempenhado por Rodrigo Duterte. Aproveitando-se de uma imagem construída ao longo do seu período enquanto prefeito em Davao, o grande mérito de Rodrigo Duterte foi canalizar em si mesmo um desejo que, apesar de latente, já circulava por entre o social e, a partir, dele lançar mão de um projeto político que toma a (in)segurança 
como uma de suas principais ferramentas de gestão. Desde as eleições em 2016, Duterte ficou marcado por ser um candidato anti-stablishment e linha dura em função de suas declarações pouco convencionais que exemplificam o caráter transgressivo da fantasia: declarou que os homicídios extrajudiciais seriam seu "único pecado" (MORALES, 2018); afirmou ter matado um outro homem a facadas aos 16 anos e culpou os centros de reabilitação por crises nacionais de escassez de alimentos (INQUIRER, 2018); xingou o ex-presidente dos Estados Unidos, Barack Obama, e uma representante da ONU de "filhos de uma prostituta" (ESTADO, 2016; ESTADO 2018); e, até mesmo, admitiu ter participado, pessoalmente, dos homicídios extrajudiciais de supostos traficantes/usuários de drogas (EL PAÍS, 2016). Não apesar disso, mas, exatamente por isso, o presidente ganha grande parte de seu capital político ao apresentar-se enquanto o único capaz de levar adiante o projeto de engrandecimento e desenvolvimento nacional.

Para além do "justiceiro" - o cavaleiro da justiça -, identificamos outras duas fantasias que Duterte, quando elevado ao posto de presidente, passa a simbolizar. São elas: o pai e o enviado divino. Enquanto "pai", Duterte é aquele que governa com punho de ferro pois ama a nação e por ela está disposto a realizar um grande sacrifício; aquele cuja forma de governar não se dá através de "subsídios sociais (concebidos enquanto uma deformação materna do Estado), e sim pela imposição da lei, da disciplina" (BUTLER, 2015, p. 170). Ao seu lado, na narrativa do enviado divino, as ações de Duterte encontram-se sob a égide de um propósito maior - ele é o próprio mensageiro dos céus que desce à Terra para fazer desaparecer o mal e permitir que a sociedade e o Estado filipinos sigam no caminho da verdade divina. Tanto a figura espectral da sociedade desenvolvida quanto as do pai e do enviado por Deus têm uma relação importante com a figura do soberano e com a forma da Lei como encenada na bio/necropolítica.

As três fantasias podem se entrecruzar e acontecer ao mesmo tempo. Da mesma forma, elas podem ocorrer em separado e em momentos específicos. Mais importante, contudo, é que, ao concatenar em si as figuras do pai, do justiceiro e do enviado divino, Duterte simboliza o soberano por excelência, aquele que, em termos schmittianos, habita o reino da anomia e tem a capacidade de decidir sobre a exceção, ou, na esteira de Mbembe, que tem a capacidade de ditar quem vive e quem morre. Ao evocar o fantasma do narco-Estado e mobilizar a narrativa do 
Estado-nação, Duterte foi capaz de mobilizar a fantasia da "boa vida" e influenciar o desejo dos indivíduos, condicionando esse objetivo a medidas duras de enfrentamento aos usuários de drogas e a um discurso sobre ordem. Aqui, fica a evidente a relação fantasia-política, uma vez que, nessa sobreposição, segurança não se resume à segurança ontológica, representada pelo resgate da identidade filipina enquanto aquilo que permite um certo grau de ancoragem, de estabilidade, de segurança para a coletividade em questão. Conforme estamos tentando desenhar, essa relação fantasia-política fica clara na mobilização da metáfora da guerra contra os usuários/traficantes de droga, por exemplo (BRASILINO, 2018)

Tão importante quanto as narrativas que atravessam a figura de Duterte para pensar a legitimação da narco-necropolítica filipina são as fantasias a respeito daquilo que se definiu como o Outro - no caso, o adicto e o traficante. O usuário de drogas é posicionado no imaginário sócio-político tanto como aquele que goza de um prazer (roubado) "perverso" e transgressor, quanto como uma subjetividade quase infecciosa, motivando o emprego da metáfora da guerra contra esse sujeito.

É frequente que o usuário de drogas seja retratado como alguém que abraça a pulsão de morte, se fazendo como um objeto de seu vício e sendo capaz de qualquer coisa para se drogar compulsivamente, oposto a uma ética de comedimento e de retidão enxergada na figura de um cidadão comum, por exemplo. Igualmente, o traficante é visto como o sujeito que age contra sua própria população, despossuído de um sentimento de pertencimento à coletividade e que trabalha para a piora das condições de vida. Nesse sentido, ambos o usuário e o traficante de drogas são aqueles contra os quais é possível fazer o dispêndio absoluto do negativo, uma vez que são construídos enquanto figuras moralmente $e$ biologicamente inferiores contra quem a única saída é a eliminação material do espaço da comunidade política da qual se fala.

Olhar sobre o caso Filipino nos permite analisar como a construção e a difusão de fantasias estão inextricavelmente ligadas com questões de (in)segurança. Em especial, a guerra às drogas promovida pela administração Duterte é um caso paradigmático para pensar como a categoria lacaniana de fantasia atravessa dimensões da distribuição da violência na teia social, evidenciando como elas constroem categorias de sujeitos e legitimam a necropolítica. 


\section{Conclusão}

O argumento que desenvolvemos no texto passou primeiramente por um caminho da psicanálise Lacaniana e a intersecção entre desejo-fantasia-sujeito, o que implica no político em compreender precisamente como certas narrativas são veiculadas e acabam moldando a maneira como os sujeitos se relacionam com a realidade e o horizonte no qual eles veem o que podem desejar e como agir coletivamente.

Longe de ser algo inofensivo, defendemos que a fantasia fornece para a necropolítica um substrato que simplifica a história amigo/inimigo e mobiliza uma série de significantes, em especial uma visão ambivalente do usuário de drogas tanto enquanto indivíduo que é um gasto de recursos quanto como alguém que goza de um prazer transgressor e proibido enquanto todos os outros se engajam em atividades produtivas enquanto cidadãos de bem.

No caso da biopolítica e sua relação com a fantasia, apesar de a última ser uma realidade da condição do sujeito, é justamente o sujeito em condição de maior vulnerabilidade que acaba sendo alvo de diversas tecnologias de controle e extermínio como as exemplificadas no texto, o que reflete as relações de poder/saber que circulam no social. Analisar a imbricação entre biopolítica e fantasia propicia que ao olharmos para a fantasia consigamos ver como essa narrativa ilustra e nos permite entender muito mais sobre tecnologias de governo que atuam materialmente.

O caso filipino é uma boa ilustração pois exacerba várias relações dentre as quais valem ser destacadas: o caráter de mobilidade da fantasia, a transgressão inerente e uma relação muito particular e violenta no que se refere aos usuários/traficantes que são definidos como o próprio inimigo e sustentados enquanto o corpo estranho que invade o social. A superidentificação ${ }^{5}$ de Duterte

\footnotetext{
${ }^{5}$ Por superidentificação aqui entendemos que Duterte acaba levando às últimas consequências o papel do soberano, expondo o núcleo violento da soberania que é bastante real, mas geralmente oculto por uma série de códigos discursivos. Para mais discussões sobre como levar uma fantasia às suas últimas consequências pode ser uma maneira de expor suas contradições, ver ZIZEK (1997) em sua discussão sobre transgressão inerente.
} 
com o próprio papel de soberano, levando-o ao seu excesso, deixa evidente o próprio núcleo violento da soberania enquanto o traçado das linhas de morte.

Desta forma, o conceito de fantasia se apresenta como um aporte conceitual valioso que nos permite repensar questões de segurança e também questões mais amplas de vida política pois consegue inserir a questão do desejo e do gozo dentro da maneira como estudamos a política. Ela ainda permite reinserir dentro da conversa uma concepção não essencialista de sujeito (decentralizado e fragmentado) que mantém uma relação constante com o desejo, nos permitindo tanto questionar como certas soluções ("objetos") colocadas são apenas fatores paliativos como perceber o próprio papel da fantasia enquanto provedora de um horizonte de desejo para o sujeito. Em última instância, interrogar a vida política através desses conceitos permite realocar a centralidade do gozo e do caráter libidinal da identificação e ação política, permitindo tanto uma visão do inconsciente enquanto fundamental para entender agências fora do modelo comum que mimetiza a soberania no nível individual quanto também para permitir entender dinâmicas de apegos que vão para além do princípio do prazer e que inscrevem o inconsciente e o fantasmático como altamente político e definidor da maneira como experienciamos o mundo diariamente (ZIZEK, 1997).

\section{Referências Bibliográficas}

AL JAZEERA. Philippines: President Duterte's allies dominate Senate race. 2019. Disponível em: https://www.aljazeera.com/news/2019/05/philippines-presidentduterte-allies-dominate-senate-race-190522061325987.html. Último acesso em: 22 de agosto de 2019.

ASPINWALL, N. Duterte Turns Death Squads on Political Activists. Foreign Policy. 2019. Disponível em: https://foreignpolicy.com/2019/06/10/duterte-turns-deathsquads-on-political-activists/. Último acesso em: 22 de agosto de 2019.

BBC, Philippine President Duterte Son denies drug involvement. Disponível em < https://www.bbc.com/news/world-asia-41189557> Acesso em 24 de janeiro de 2020

BERLANT, L. Desire. In: STIMPSON, C. R. (Org); HERDT, G. (Org). Critical terms for the study of gender. University of Chicago Press, 2014.

BERLANT, L. Love. In: STIMPSON, C. R. (Org); HERDT, G. (Org). Critical terms for the study of gender. University of Chicago Press, 2014. 
BERLANT, L. "Cruel Optimism" Duke University Press, New York, United States, 2013

BIGO, Didier. International Political Sociology In: WILLIAMS, Paul D. (Org.) "Security Studies: An Introduction", Routledge, New York, 2008

BIGO, D. WALKER, R.B.J "Political Sociology and the problem of the International", Millennium: Journal of International Studies, Vol.35 No.3, pp. 725-739, 2007.

BUTLER, J. Quadros de guerra: quando a vida é passível de luto. Rio de Janeiro: Civilização Brasileira, v. 2009, 2015.

BUTLER, J. A vida psíquica do poder: teorias da sujeição. São Paulo, Autêntica, 2017.

BUZAN, B.; WAEVER, O.; DE WILDE, J. Security: a new framework for analysis. Boulder: Lynne Rienner, 1998

CALIWAN, C. L. Firing squad for drug traffickers: Senator-elect Bato. Phillipines News Agency. 2019. Disponível em: https://www.pna.gov.ph/articles/1073367. Último acesso em: 22 de Agosto de 2019.

DOLAR, M. "Cogito as the subject of the unconscious" In Cogito and the unconscious ed. Slavoj Zizek, Duke University Press, London, 1998.

DW. Duterte plans anti-communist 'death squad' in Philippines. 2018. Disponível em: https://www.dw.com/en/duterte-plans-anti-communist-death-squad-in-philippines/a46484215. Último acesso em: 22 de agosto de 2019.

EBERLE, J. Narrative, desire, ontological security, transgression: fantasy as a factor in international politics. Journal of International Relations and Development, v. 22, n. 1, p. 243-268, 2019.

EDKINS, J. Poststructuralism \& international relations: Bringing the political back in. Londres, Lynne Rienner Publishers, 1999.

FOUCAULT, M. Segurança, território, população. São Paulo: Martins Fontes, 2008.

FOUCAULT, M. Em defesa da sociedade: curso no Collège de France (1975-1976). São Paulo: Martins Fontes, 2010.

GLYNOS, J.; STAVRAKAKIS, Y. Lacan and political subjectivity: Fantasy and enjoyment in psychoanalysis and political theory. Subjectivity, v. 24, n. 1, p. 256-274, 2008.

INQUIRER, Duterte Jokes: Rice shortage fault of drug addicts in rehab centers. The Inquirer. 27 de setembro de 2018. Disponível em $<$ https://newsinfo.inquirer.net/1037041/duterte-jokes-rice-shortage-fault-of-drugaddicts-in-re hab-centers> 
KRAUSE, K.; Michael, C. W. Broadening the Agenda of Security Studies: Politics and Methods. Mershon International Studies Review. Vol. 40 (1996); pp. 229-254.

KRAUSE, K.; Michael, C. W. Security and 'Security Studies: Conceptual Evolution and Historical Transformation. In GHECIU, A.; WILLIAM, C. W. (Orgs.) The Oxford Handbook of International Security. Oxford: Oxford University Press, 2018; pp. 1428.

LACAN, J. "Escritos" "Escritos", Campo Freudiano no Brasil, Zahar, Rio de Janeiro, Brasil, 1998

LACAN, J. The Seminar. Book II. The Ego in Freud's Theory and in the Technique of Psychoanalysis, 1954-55. Trans. Sylvana Tomaselli. New York: Nortion; Cambridge: Cambridge Unviersity Press, 1988

LAPLANCHE J.; PONTALIS, J. B. The Language of Psychoanalysis, Polestar Wheatons, Reino Unido, 1973

MANDELBAUM, M. M. State, nation, society: The congruency fantasy and in/security of the body-national/social. Critical Studies on Security, v. 4, n. 2, p. 187-201, 2016.

MARU, D. CHR chief: Drug war deaths could be as high as 27,000. CBS. 2018. Disponível em: https://news.abs-cbn.com/focus/12/05/18/chr-chief-drug-war-deathscould-be-as-high-as-27000. Último acesso em: 22 de agosto de 2019.

MBEMBE, A. Políticas da inimizade. Lisboa, Antígona, 2017.

MBEMBE, A. Necropolítica: Biopoder, soberania, estado de exceção. Rio de Janeiro: n-1 edições, 2018.

MORALES, N.J. Philippines Rodrigo Duterte appears to admit to extrajudicial killings saying they're his 'only sin'. REUTERS. 28 de setembro de 2018. Disponível em $<$ https://globalnews.ca/news/4496223/duterte-extrajudicial-killings-only-sin/> Acesso em: 2 de outubro

O ESTADO DE SÃO PAULO, Presidente filipino diz que matou uma pessoa a facadas quando tinha 16 anos O Estado de São Paulo. 10 de novembro 2017. Disponível em <https://internacional.estadao.com.br/noticias/geral,presidente-filipinodiz-que-matou-uma-pe ssoa-a-facadas-quando-era-adolescente,70002079379>

Acesso em: 1 de outubro

O ESTADO DE SÃO PAULO, Assim é Rodrigo Duterte, o presidente filipino que chamou Obama de 'filho da puta. O Estado de São Paulo. 7 de setembro de 2016. Disponível em <https://brasil.elpais.com/brasil/2016/09/06/internacional/1473146836_639450.html> Acesso em: 1 de outubro

O ESTADO DE SÃO PAULO. Rei dos insultos, Duterte chama oficial da ONU de 'filho de uma prostituta O Estado de São Paulo. 5 de abril de 2018. Disponível em 
$<$ https://br.sputniknews.com/asia oceania/2018040510917488-duterte-onu-filhoprostituta/> Acesso em: 1 de outubro

SANTOS, V. O. The Philippines Just Became More Authoritarian, Thanks to the People. The New York Times. 2019. Disponível em: https://www.nytimes.com/2019/05/24/opinion/philippines-duterte-electionsenate.html. Último acesso em: 22 de agosto de 2019.

SOLOMON, T. Psychoanalytic Theory and Textual Interpretation. In: Interpretation in Political Theory. San Diego, Routledge, 2016. p. 219-242.

STAVRAKAKIS, Y. Lacan and the political (Thinking the political). San Diego, Routledge, 1999.

THE WASHINGTON POST. The U.N. must seek out the truth on Duterte's death squads. 2019. Disponível em: <https://www.washingtonpost.com/opinions/globalopinions/the-un-must-seek-out-the-truth-on-dutertes-death-

squads/2019/06/13/ee211a42-8d2f-11e9-b08ecfd89bd36d4e story.html?utm term=.43ae302f260e > Acesso em: 22 de agosto de 2019.

THE WORLD BANK. Philippines to Sustain Strong Growth amidst Local and Global Uncertainties. 2019. Disponível em:<https://www.worldbank.org/en/news/pressrelease/2019/04/01/philippines-to-sustain-strong-growth-amidst-local-and-globaluncertainties> Acesso em: 22 de agosto de 201

WALKER, R.B.J. "Inside/outside: International Relations as Political Theory" Cambridge, Cambridge University Press, 1993

WALKER, R.B.J "International Inequality", International Studies Association, Blackwell Publishing, Oxford and Malden, United Kingdom and United States, 2002

WALKER, R.B.J "The double outside of the modern international", Ephemera, 6(1): 56-69, 2006

ZEVNIK, A. Lacan, Deleuze and world politics: Rethinking the ontology of the political subject. San Diego, Routledge, 2016.

ŽIŽEK, S. Fantasy as a political category: A Lacanian approach in Journal for Psychoanalysis of Culture and Society 1, pp. 77-85. 1996.

ŽlŽEK, S. The plague of fantasies. Nova York, Verso, 1997. 